Proceedings

\title{
Planning of Energy Production and Management of Energy Resources in Local Energy Communities: The Case of Berchidda Municipality (Italy) ${ }^{\dagger}$
}

\author{
Andrea Giordano ${ }^{1}$, Emilio Ghiani ${ }^{1, *}$, Fabrizio Pilo ${ }^{1}$ and Luca Rosetti ${ }^{2}$ \\ 1 Department of Electrical \& Electronic Engineering, University of Cagliari, Piazza d'Armi, \\ 09123 Cagliari, Italy \\ 2 Consorzio S.I.E.S. - Sviluppo Integrato per le Energie Sostenibili, Via Caboni 10, 09123 Cagliari, Italy \\ * Correspondence: emilio.ghiani@diee.unica.it; Tel.: +39-070-675-5872 \\ + Presented at the Sustainable Places 2019 (SP 2019), Cagliari, Italy, 5-7 June 2019.
}

Published: 24 July 2019

\begin{abstract}
This paper aims to present the ideas and the strategies behind the project called "Berchidda Energy 4.0" which proposes the development of a smart Local Energy Community in the Municipality of Berchidda (Italy). The project is focused on increasing energy efficiency by fostering renewable generation production and maximizing the self-consumption of the energy produced, as well as increasing the active involvement of the consumers that will be equipped with smart home automation system for demand response applications.
\end{abstract}

Keywords: local energy community; smart grid; distributed energy resources; renewable energy sources

\section{Introduction}

Nowadays, energy systems across the globe are going through a radical transformation as a result of technological changes that follows the persisting growth of variable renewable generation predominantly at distribution level - that is gradually altering the operating conditions of both electricity transmission and distribution networks. In particular, the power distribution sector is foreseen to be the more involved in the evolution of the power system towards future smart grid scenarios, in which active networks will be more intelligently capable to integrate renewable energy sources (RES), demand side response (DSR) and energy storage systems (ESS). The transition towards smart distribution networks (SDN) will require the implementation of new concepts with novel electrical system structure as well as the addition of novel types of control systems and equipment able to manage bidirectional power flows, according to new policy and regulatory frameworks. The increasing of deployment of distributed energy resources (DERs) requires the reorganization of the management of energy systems according to Smart Grid paradigm [1]. Indeed, power generation and transmission in conventional power systems are actively controlled to balance the demand, but there is no active management in distribution and demand level of the system [2].

Among those new concepts for power distribution and utilization, there is the Local Energy Community (LEC), that is the economic and operational participation and/or ownership of Distributed Generators (DG) and ESS by citizens or members of a community (e.g. Municipality, district, etc.).

Typical aim of the energy community is the cooperation to:

- reduce the energetic dependence on the utility grid,

- minimize the energy bill for the users,

- enhance of the self-consumption, 
- trade the overproduction of the energy with others and sell ancillary services to network operators.

Although there is no a reference model for the development of LECs, since May 2018 regulatory framework is evolving, and the changes are sensitive to the European directives contained in the Clean Energy Package (CEP) [3], which seeks to promote the development of the LEC and to give a special role to citizens in the management of the self-produced energy.

\section{2. "Berchidda Energy 4.0" Project}

\subsection{Current Situation}

The municipality of Berchidda (Sardinia, Italy), in Figure 1a, through the Azienda Elettrica Comunale (A.E.C., i.e. "Municipal Power Company") [4] and according with the Italian Ministry of Industry [5], is the owner of the local MV/LV distribution network and holds the license for the energy distribution, sale and delivery to the final consumers.

As of today, the municipality of Berchidda and the A.E.C. are engaged in an upgrading of the own distribution energy infrastructure.

In particular, the first phase of the project involves the acquisition of the rural electricity network, currently owned by the DSO, which includes $13 \mathrm{MV} / \mathrm{LV}$ substation.

However, for the present study only the residential area, Figure $1 \mathrm{~b}$, and the related power grid will be considered.

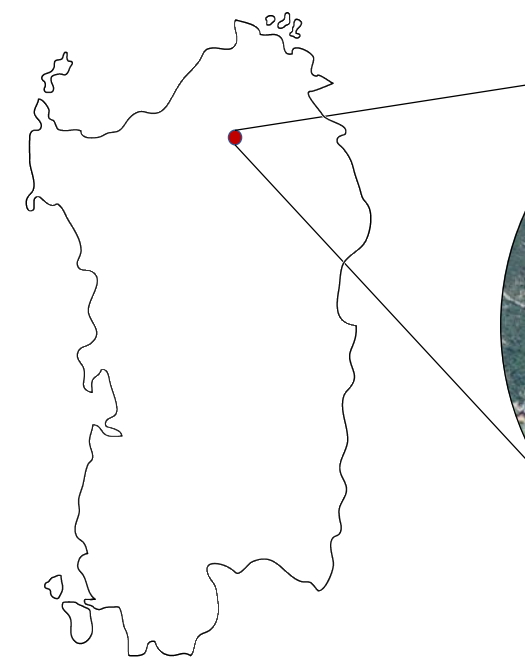

(a)

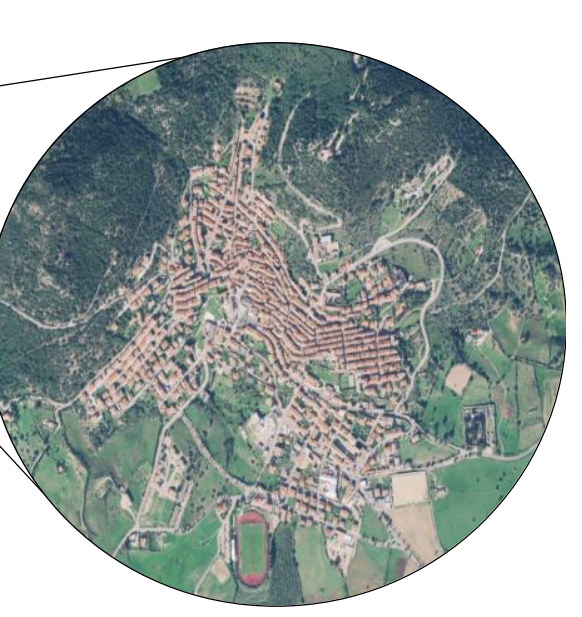

(b)

Figure 1. (a) Sardinia island (b) Municipality of Berchidda-Urban network.

The Table 1 shows the different types of users and the related energy purchase from the public grid.

Table 1. Berchidda customers types and related energy purchase from the public grid.

\begin{tabular}{ccccc}
\hline Customer Type & \# Customers & $\begin{array}{c}\text { Voltage } \\
\text { Level }\end{array}$ & $\begin{array}{c}\text { Power Installed } \\
{[\mathbf{k W}]}\end{array}$ & $\begin{array}{c}\text { Energy Consumed } \\
\text { [MWh/y] }\end{array}$ \\
\hline Residential (household) & 1051 & LV & 3209 & 2761 \\
Public buildings & 259 & LV & 797 & 301 \\
Commercial \& Industrial & 292 & LV & 1666 & 2316 \\
MV consumers & 2 & MV & 346 & 269 \\
Public lighting & $/$ & LV & 246 & 414 \\
\hline Total & 1626 & $/$ & 6234 & 6061 \\
\hline
\end{tabular}


The average load profile of the Municipality of Berchidda is shown in Figure 2, distinguishing the gross load and the net load and considering the $67 \mathrm{PV}$ plants for $608 \mathrm{kWp}$ already installed.

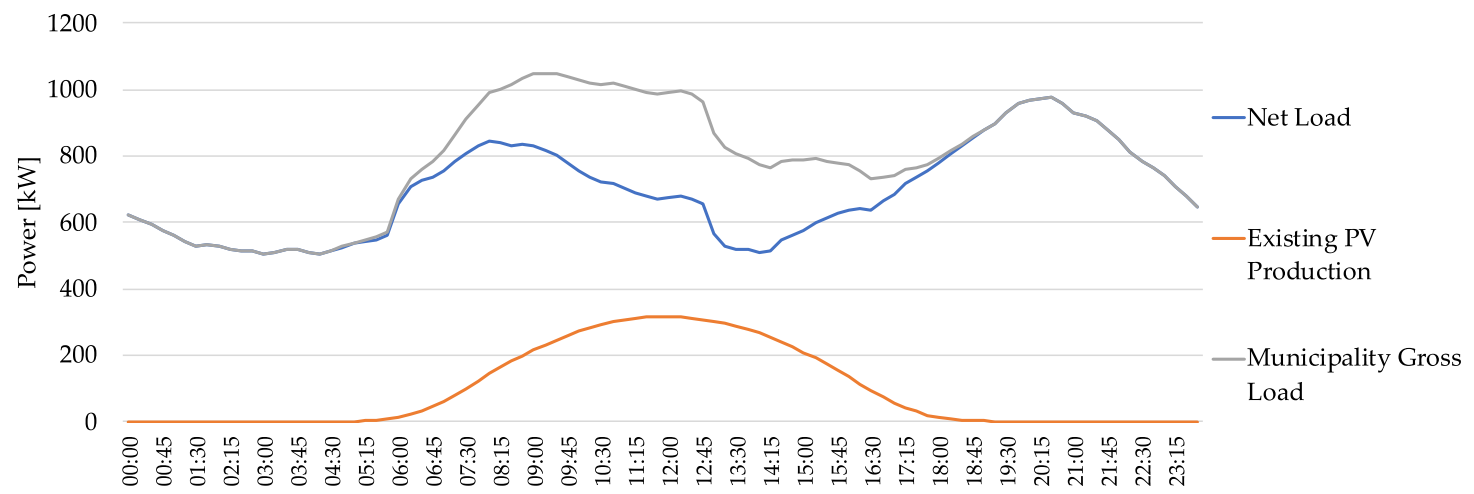

Figure 2. Current load profile and PV production in Berchidda urban network.

The area between the blue curve and the gray curve represents the energy produced by the PV plant and self-consumed: while the energy purchases from the grid is about $16.4 \mathrm{MWh} / \mathrm{d}$, the mean daily gross electric load is approximately of $19 \mathrm{MWh} / \mathrm{d}$, which amount to $6.9 \mathrm{GWh} / \mathrm{y}$.

\subsection{Pillars of the Project}

The ambition of the project is to make the municipality of Berchidda a LEC and it's founded on the mainstays reported in Table 2.

Table 2. Mainstays of the project.

$\# \quad$ Action

1

Active involvement of the consumers by the smart home automation system equipped with the Demand Side Management System (DSMS).

Energy production by renewable sources (mostly by photovoltaic plant) and exploitation of the Energy Storage System (ESS), both controlled according with the SG paradigm.

Deployment of new energy carrier and technological solution for energy's both production and storage.

\subsubsection{Active Involvement of the Consumers}

In order to successfully manage energy transitions, the involvement and support of citizens is essential. This LEC project provides the opportunity for citizens to actively engage in the community and the local energy system. Rather than participating as mere energy consumers, members of the public are currently able to assume a number of different roles within the energy system, as they are able to influence the ways and the extent to which energy is produced [6]. Indeed, to increase the portion of self-consumed energy is necessary proceed through the strategies of demand control or the load shifting. It consists of making sure that most of the consumptions occur during the day, and specifically during the hours when PV plants are producing, with the aim to use instantly the energy produced. This is the reason why the first action consists of equipping the community of Berchidda with Smart Meters (SM) for the real time consumption monitoring and for the dispatch to the single user/prosumer of messages and advices for an efficient energy use. A cloud platform manages the information obtained by the SM with the purpose of calculate the optimum level of consumption/production, according also with the forecasts of an Artificial Intelligence (AI) application. Citizens participating in the project will be provided with an App which send them a set of daily information/requests on the base of the consumption profile desired. In particular, every day 
the users/prosumers receive the notice about the best time to play the household appliances. Thanks to this philosophy, a load-shifting of the $20 \%$ (almost $800 \mathrm{kWh} / \mathrm{d}$ ) from evening hours to the PV production hours is expected. Furthermore, how demonstrated in [7], if aware of their energy consumption, the residential final-users (which have an impact of the $50 \%$ on the total Berchidda's load) reduce automatically their off-takes from the grid of $8 \%$. Quantitatively, it translates into an average overall energy saving of about $700 \mathrm{kWh} / \mathrm{d}$ (represented by the area between the blue curve and the gray curve in Figure 3) corresponding to about $255 \mathrm{MWh} / \mathrm{y}$, or $4 \%$ of the total annual consumption.

The expected load profile resulting from this action is represented by the blue curve in Figure 3.

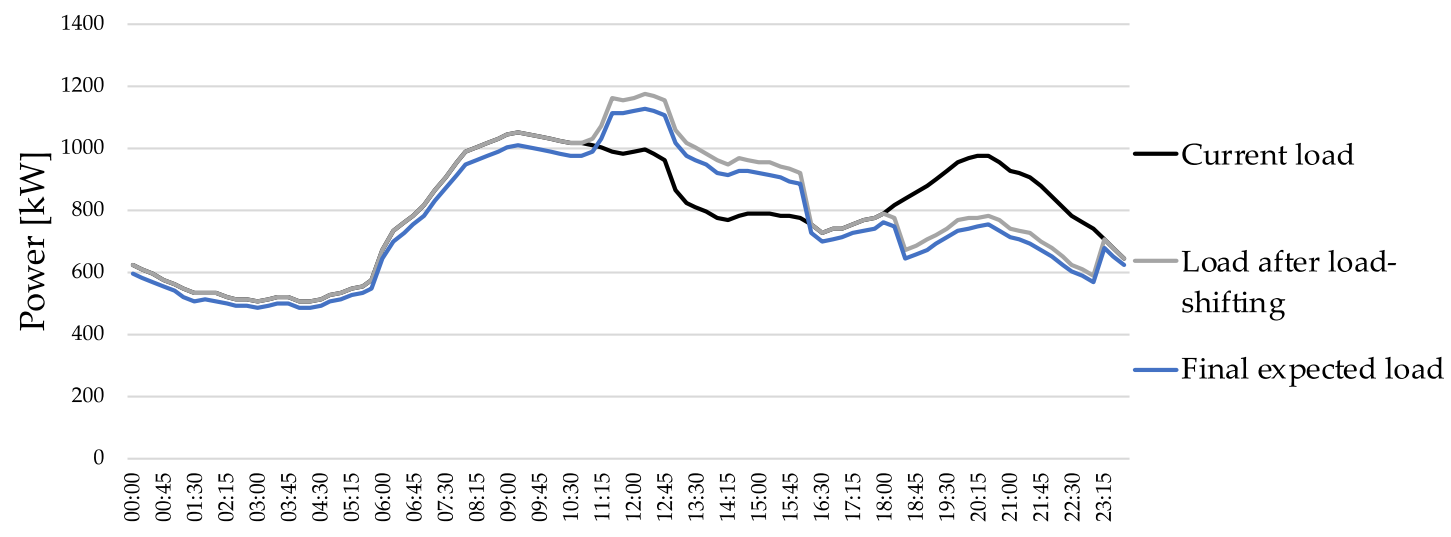

Figure 3. Load-shifting effect.

\subsubsection{Energy Production by Renewable Sources}

The project aims to install $1500 \mathrm{kWp}$ of PV plants (besides the $608 \mathrm{kWp}$ already installed) by exploiting the rooftops of both private and public buildings. The number of the rooftops depends on the citizens' interest in the project, but at least 200 micro PV systems are expected. Under these assumptions, the total PV production is summarized in Table 3.

Table 3. Berchidda's PV production.

\begin{tabular}{ccc}
\hline PV System & Power [kWp] & Energy [kWh/y] \\
\hline Existing PV & 608 & 820,000 \\
New PV & 1500 & $2,000,000$ \\
\hline Total & 2108 & $2,820,000$ \\
\hline
\end{tabular}

In order to support the management of the PV system, at least 30 pilot projects small size Li-Ion ESS ( $3 \mathrm{~kW} / 10 \mathrm{kWh}$ ) will be installed. This distributed ESS, suitably coordinated by a central energy management system (EMS) and local energy management systems at user location (EMU) (Figure 4), compensates the power fluctuations caused by RES production's variability and retrieves the energy that cannot be used instantaneously, with the purpose of maximize the self-consumption and minimize the energy purchase from the main grid. Furthermore, other 4 ESS, each of $50 \mathrm{kWh}$, are planned to be positioned in $4 \mathrm{MV} / \mathrm{LV}$ substation, with the aim of smoothing the global load curve. 


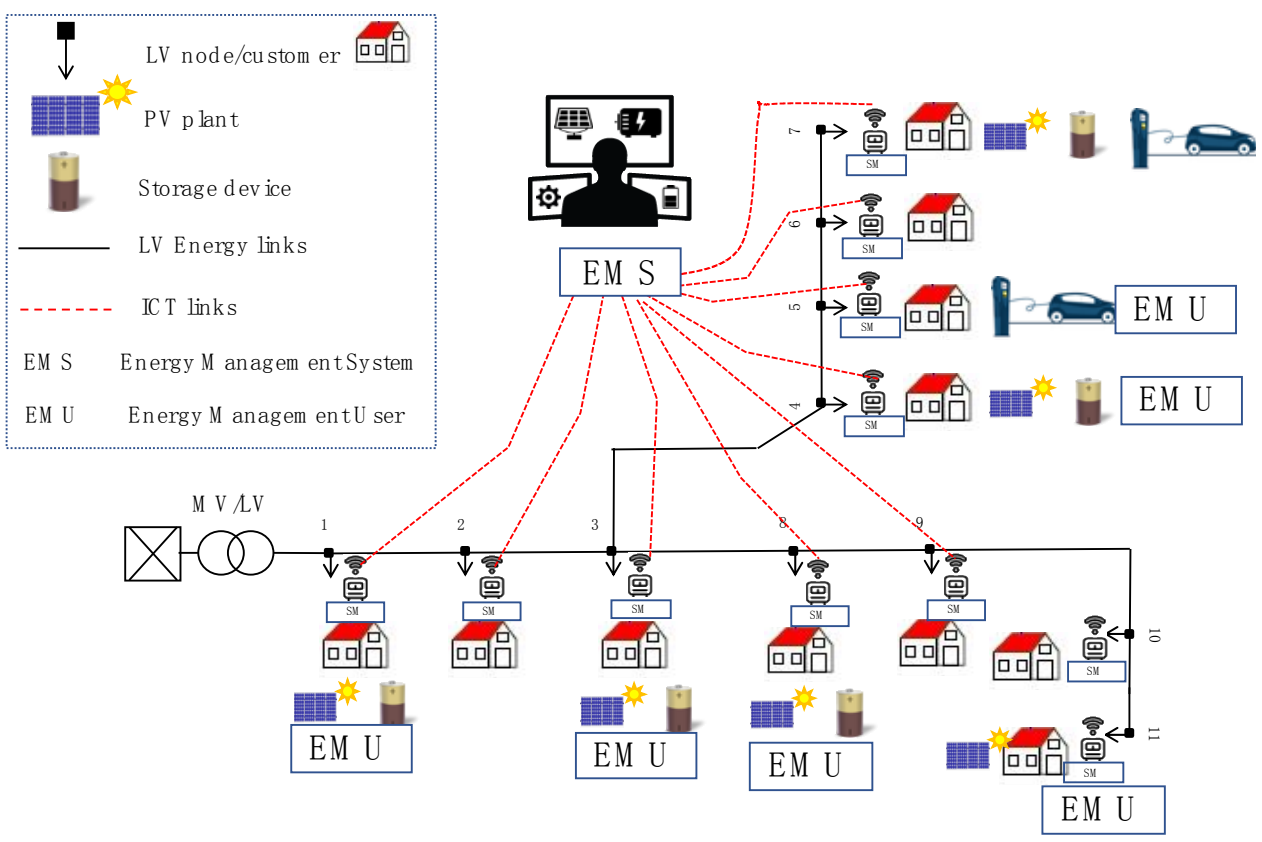

Figure 4. Future LV distribution grid.

\subsubsection{Deployment of New Energy Carrier}

Although the region of Sardinia has not a natural gas distribution infrastructure yet, it can be imported from the mainland in the form of LNG. This energy resource enables the utilization of available technologies such as Fuel Cells and Microturbine plants in combined heat and power (CHP) configuration. Following this opportunity, the installation of one dispatchable plant of $200 \mathrm{kWe}$ is planned to be used near of users with high heat demand for both residential and industrial purposes.

By combining the citizens contribution to the load shifting, the new PV plants, the ESS and the dispatchable source contribution, the final LEC's load profile is represented with the orange curve in Figure 5.

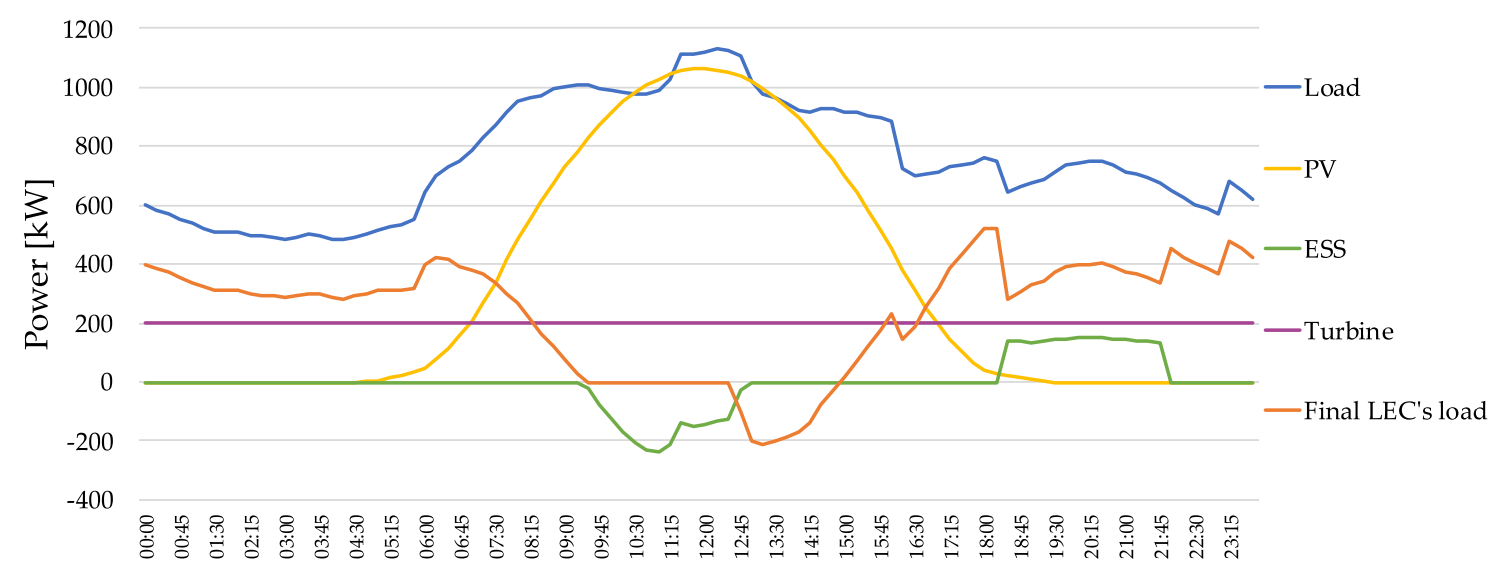

Figure 5. Final daily LEC's load profile.

Thanks to this new local grid structure, on average, in the LEC the energy purchases can be reduced of over $66 \%$, from $16,400 \mathrm{kWh} / \mathrm{d}$ to $5600 \mathrm{kWh} / \mathrm{d}$ and it reaches a self-consumption near $95 \%$. Finally, the Table 4 summarizes all the actions envisaged in the project and its effect of reduction of energy purchase from the grid. 
Table 4. Project effects on the energy purchases.

\begin{tabular}{cc}
\hline Smart Grid Action & Expected Reduction of Energy Purchases from the Grid \\
\hline PV and Storage & $-30 \%$ \\
Demand/Response \& Smart Metering & $-4 \%$ \\
CHP Plant & $-28 \%$ \\
Network Losses & $-4 \%$ \\
\hline
\end{tabular}

\subsection{Economic Analysis of the Smart Grid Actions}

Currently, the energy cost allocation for the A.E.C. are as shown in Table 5, for a total amount of $1.342 \mathrm{M} € / \mathrm{y}$, and the planned actions can reduce all the cost of the municipality of Berchidda.

Table 5. Energy costs allocation.

\begin{tabular}{ccc}
\hline Tariff Component & Current Amount [€/y] & Expected Amount [€/y] \\
\hline Energy & 632,000 & 215,000 \\
Transmission \& Metering & 239,000 & 81,000 \\
System charges & 471,000 & 376,000 \\
\hline Total & $1,342,000$ & 672,000 \\
\hline
\end{tabular}

In particular, since the quantity of energy purchases will decrease of $66 \%$, the amount for energy and for transmission\&metering fees will be expected consequently falling. Although the system charges take into account some standing charges that cannot be removed, the new smart energy infrastructure will lead economic savings for the LEC's final users that are expected to be of more than $20 \%$ of the total electricity costs.

Funding: This research was funded by Municipality of Berchidda. Development and Cohesion Fund 2014-2020. Pact for the development of the Region Sardinia. Action line 1.6.2-Transformation of the Sardinian Energy System towards an integrated and intelligent configuration (Sardinian Smart Energy System).

Conflicts of Interest: The authors declare no conflict of interest.

\section{References}

1. Tuballa, M.L.; Abundo, M.L. A Review of the Development of Smart Grid Technologies. Available online: https://www.sciencedirect.com/science/article/pii/S1364032116000393 (accessed on 24 July 2019).

2. Sousa, T.; Soares, T.; Pinson, P.; Moret, F.; Baroche, T.; Sorin, E. Peer-to-Peer and Community-Based Markets: A Comprehensive Review. Available online: https://www.sciencedirect.com/science/article/pii/ S1364032119300462 (accessed on 24 July 2019).

3. Clean Energy for all Europeans. Available online: https://ec.europa.eu/energy/en/topics/energy-strategyand-energy-union/clean-energy-all-europeans (accessed on 24 July 2019).

4. Azienda Elettrica Comunale. Available online: https://comune.berchidda.ot.it/it/page/azienda-elettricacomunale (accessed on 24 July 2019).

5. Ministero dello Sviluppo Economico. Available online: https://www.mise.gov.it/index.php/it (accessed on 24 July 2019).

6. Kalkbrenner, B.J.; Roosen, J. Citizens' Willingness to Participate in Local Renewable Energy Projects: The Role of Community and Trust in Germany. Available online: https://www.sciencedirect.com/science/ article/pii/S2214629615300864 (accessed on 24 July 2019).

7. ADDRESS Project-FP7 ENERGY. Available online: http://www.addressfp7.org/ (accessed on 24 July 2019). 